\title{
Satellite Observations of Seasonal and Interannual Changes of Sea Level and Currents over the Scotian Slope
}

\author{
GUOQI HAN \\ Northwest Atlantic Fisheries Centre, Fisheries and Oceans Canada, St. John's, Newfoundland, Canada
}

(Manuscript received 15 December 2005, in final form 15 May 2006)

\begin{abstract}
Seasonal and interannual sea level and current variations over the Scotian slope are examined using 10 years of Ocean Topography Experiment (TOPEX)/Poseidon (T/P) satellite altimeter data. Geostrophic surface current anomalies normal to ground tracks are derived from the along-track gradients of sea level anomalies. The altimetric current anomalies are combined with a climatological mean circulation field of a finite-element model to construct nominal absolute currents. The seasonal mean results indicate that the sea level is highest in late summer and lowest in late winter and that the surface slope circulation is strong in winter/autumn and weaker in summer/spring. The total transport associated with the westward shelf-edge current and with the eastward slope current, calculated by combining the T/P data with a climatological seasonal mean density field, reveals a substantial seasonal change dominated by the barotropic component. The present analysis reveals prominent interannual changes of the sea level and current anomalies for the study period. The sea level was lowest in 1996/97, when the Gulf Stream was in its most southern position. The mean winter circulation over the Scotian slope was strongest (up to $30 \mathrm{~cm} \mathrm{~s}^{-1}$ in both the southwestward shelf-edge current and northeastward slope current) in 1998 and weakest (weaker and broader shelf-edge current) in 1996, which may be related to the fluctuation of the equatorward Labrador Current strength and of the Gulf Stream north-south position. The study also suggests that the root-mean-square current magnitude is positively correlated with the occurrence of the Gulf Stream warm-core rings (WCRs) on the interannual scale, while WCR yearly mean kinematic properties seem to have small variations.
\end{abstract}

\section{Introduction}

The "Scotian slope" (Fig. 1) and "rise" are located on the eastern end of the "Slope Sea" (Csanady and Hamilton 1988). As part of a broad slope-water cyclonic circulation, the shelf-edge current carries Labrador Current water of Arctic origin and the Gulf of St. Lawrence outflow water southwestward along the shelf break and upper continental slope (Han et al. 1999), while the slope current transports warmer and more saline water northeastward along the lower continental slope and rise, north of the Gulf Stream. The variability of slope water circulation is strongly influenced by Gulf Stream meanders and anticyclonic warm-core rings (WCRs) (Joyce 1991; Han 2004a). Both the shelf/slope front and the Gulf Stream northern boundary fluctuate

Corresponding author address: Guoqi Han, Northwest Atlantic Fisheries Centre, Fisheries and Oceans Canada, St. John's, NL A1C 5X1, Canada.

E-mail: hang@dfo-mpo.gc.ca on various time and space scales, including seasonal and interannual variability (Drinkwater et al. 1994).

Petrie and Drinkwater (1993) reported substantial interannual and decadal changes in hydrographic properties off Nova Scotia, which were associated with the Labrador Current variability. An annual cycle of geostrophic sea surface currents over the Scotian shelf and slope was derived from Geosat altimeter data (Han et al. 1993), indicating that the shelf edge surface current was strong in winter and weak in summer. Pickart et al. (1999) investigated the mean structure of an eastward slope current and its interannual variability over the eastern Scotian slope and the southwestern Newfoundland slope. They found that the slope current position and strength fluctuates in correlation with the variability of the Labrador Current on interannual scales. The entire upper-layer slope water circulation spins up/ down on interannual scales, coincident with strengthening/weakening of the overflow component of the deep western boundary current. Fratantoni (2001) described the North Atlantic Ocean surface circulation during the 1990s from satellite drifter data. Their re-

DOI: $10.1175 / \mathrm{JPO} 3036.1$ 


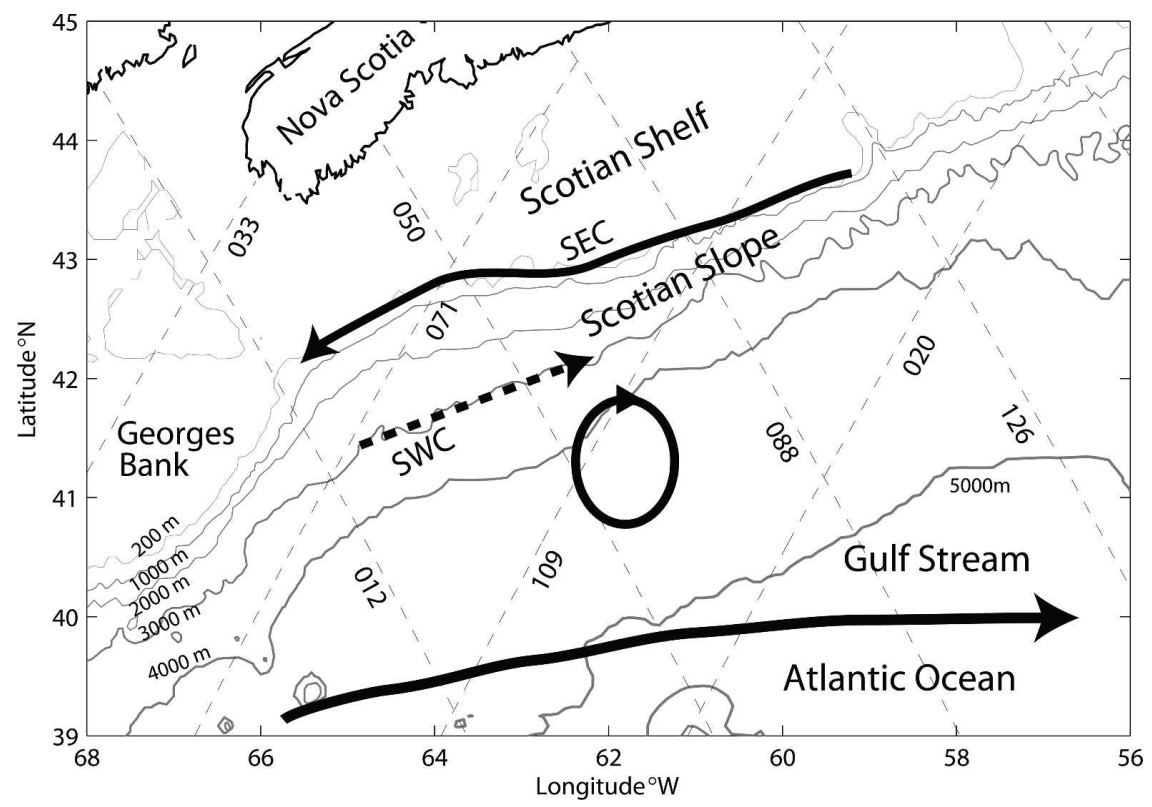

FIG. 1. Map showing the Scotian slope and adjacent shelf and deep oceans with a schematic representation of the circulation. The labeled lines are the selected T/P ground tracks on which the analysis is performed. SEC: shelf-edge current; SWC: "slope water" current. The ellipse depicts a Gulf Stream ring.

sults revealed equatorward flow along the shelf edge off the northeastern Grand Bank and off Georges Bank, but not off the Scotian shelf. Loder et al. (2001), using historical data, geostrophic computations, and numerical circulation models, examined decadal-scale hydrographic "regime shifts" and associated circulation changes in the Scotian shelf and Gulf of Maine region. Their analyses of ocean temperature and salinity data indicate multiyear periods with cooler and fresher conditions over the shelf and slope around 1940 and 1960, apparently associated with increased Labrador Current transport. Han (2002) from the Ocean Topography Experiment (TOPEX)/Poseidon (T/P) data studied the interannual sea level variability from the Scotian shelf to the Middle Atlantic Bight in the 1990s. It has been found that the Labrador Current transport and the Gulf Stream position experienced significant interannual changes in the past decade (Han 2002). Han et al. (2002) investigated the annual cycle of the surface currents over the Scotian shelf and slope using T/P altimetric data and circulation model results. Mesoscale current variability over the Scotian slope was studied from $\mathrm{T} / \mathrm{P}$ and frontal analysis data for the period of 1992-2002 (Han 2004a).

In this study we use $\mathrm{T} / \mathrm{P}$ altimeter data to examine seasonal and interannual sea level and current variability over the Scotian slope and rise using satellite altimetric and infrared observations. Seasonal and inter- annual features of altimetric sea level, currents, and WCRs are presented and discussed, in conjunction with frontal analysis data digitized from satellite imagery $(\mathrm{K}$. Drinkwater and R. Pettipas 2003, personal communication).

This article consists of five sections. In section 2, the T/P data and processing techniques, derivation of surface currents, and frontal analysis data are described. Section 3 presents seasonal sea level, current variability, and compares altimetric results with steric heights and model solutions. Interannual sea level and current changes are discussed in the section 4 . Section 5 concludes the paper.

\section{Methodology}

\section{a. T/P altimeter data}

TOPEX/Poseiden altimetric sea surface height data, corrected based primarily on the principles in Benada (1997) for various atmospheric and oceanographic effects and obtained from the National Aeronautics and Space Administration (NASA) Pathfinder Project, are the primary data sources in this study. Four ascending tracks and four descending tracks were selected across the Scotian slope and rise off Nova Scotia (Fig. 1). The satellite repeats its ground track every 10 days. The along-track resolution is about $6 \mathrm{~km}$ and the cross-track spacing is about $220 \mathrm{~km}$. The standard NASA Goddard 
Space Flight Center precise orbit based on the Joint Gravity Model-3 has been used to produce the sea surface height data. There are nominally $360 \mathrm{~T} / \mathrm{P}$ observations (September 1992-July 2002) at each data location.

The corrected sea surface height data were used to generate a mean sea surface height at each location. We then calculated the sea surface height anomalies relative to the mean sea surface. Both the marine geoid and mean oceanic topography are removed by this procedure. An along-track digital filter with an approximate $e$-folding scale of $18 \mathrm{~km}$ was applied to reduce noise influences on the current estimates. The results presented will be based on the smoothed height data unless indicated otherwise. The sea surface height anomaly profiles for Track 050 on 1 June 1993 and on 3 October 1996 are shown in Fig. 2a. The results show significant temporal and spatial sea level changes.

\section{b. Calculation of sea surface currents}

From the smoothed altimetric sea surface height anomalies, we derived geostrophic surface current anomalies (Fig. 2b). Note that these are estimates of
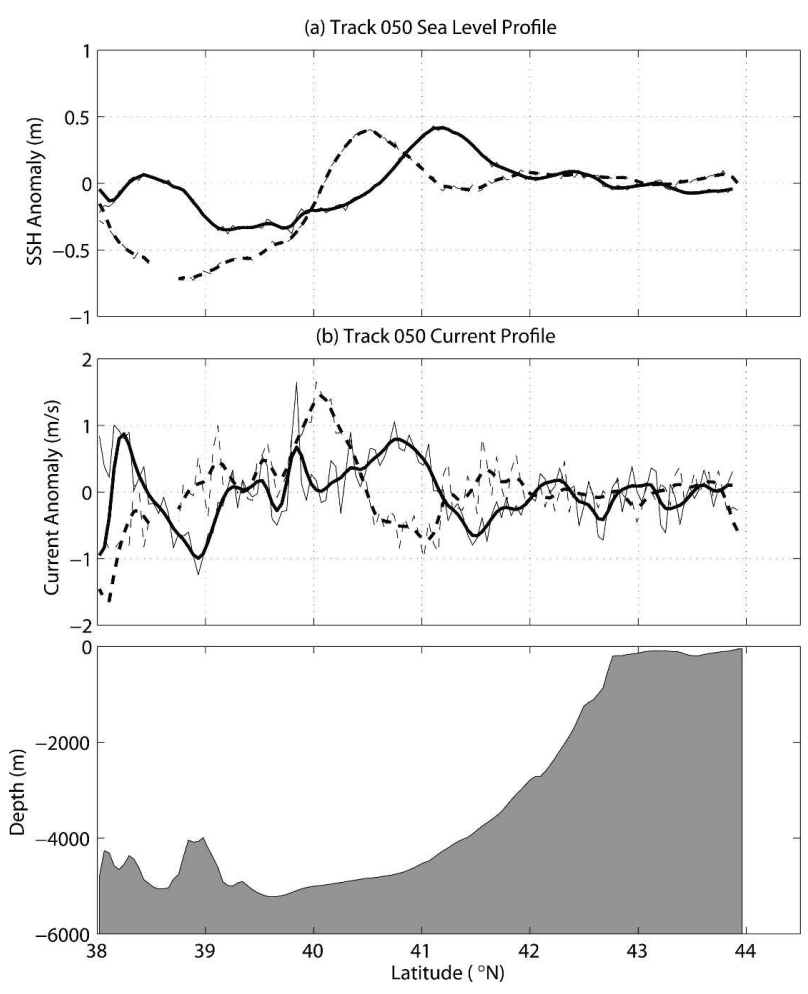

FIG. 2. (a) Along-track profiles of $\mathrm{T} / \mathrm{P}$ sea surface height anomalies for Track 050 on 1 Jun 1993 (solid line) and 3 Oct 1996 (dashed line): unsmoothed (thin line) vs smoothed with the digital filter (thick line). (b) Associated cross-track geostrophic currents. The ocean bottom topography is shown in the lower panel.

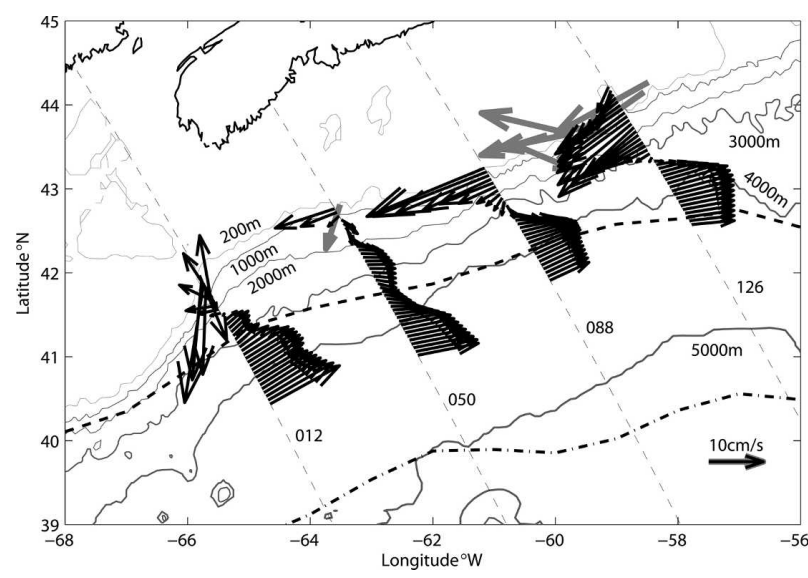

FIG. 3. Climatological mean surface currents over the Scotian slope derived from Han et al.'s (1997) model results. The thicker gray arrows are monthly mean currents estimated from historical moored measurements. Also depicted are mean positions of the shelf/slope front (thick dashed lines) and the Gulf Stream northern boundary (dash-dotted lines) for the study period.

surface current anomalies normal to the satellite ground tracks about the mean only, associated with the along-track pressure gradient derived from the slope of the sea surface height anomalies. We will focus on the current anomalies on the descending tracks since they are approximately perpendicular to the dominant mean flow direction over the Scotian slope.

An approximate way of constructing absolute surface currents is to combine altimetric current anomalies with

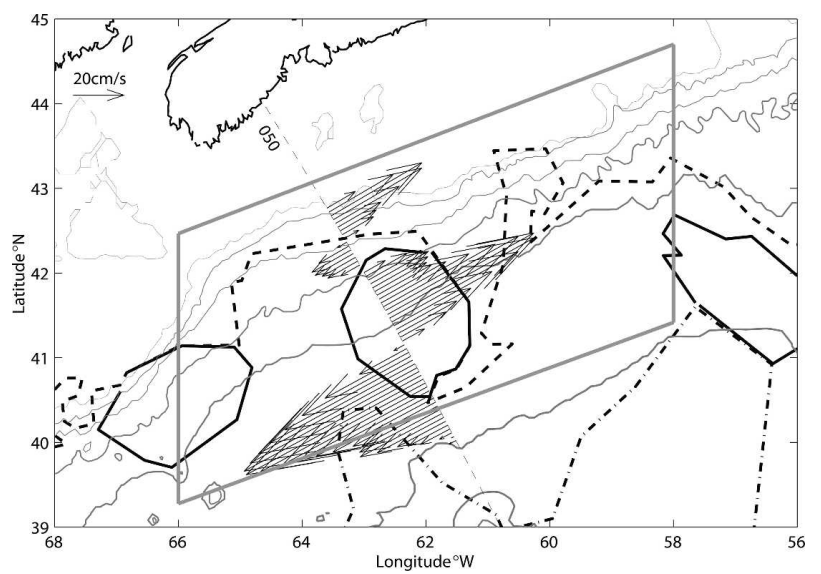

FIG. 4. The positions of the Gulf Stream northern boundary (dash-dotted line) and shelf-slope front (dashed line) and the WCRs (solid line) derived from satellite thermal imagery for the week of 2 Jun 1993. The arrows are the T/P-derived geostrophic current anomalies normal to Track 050 . The gray polygon depicts the area within which the WCRs are counted for the calculation of statistics in section 4 . 

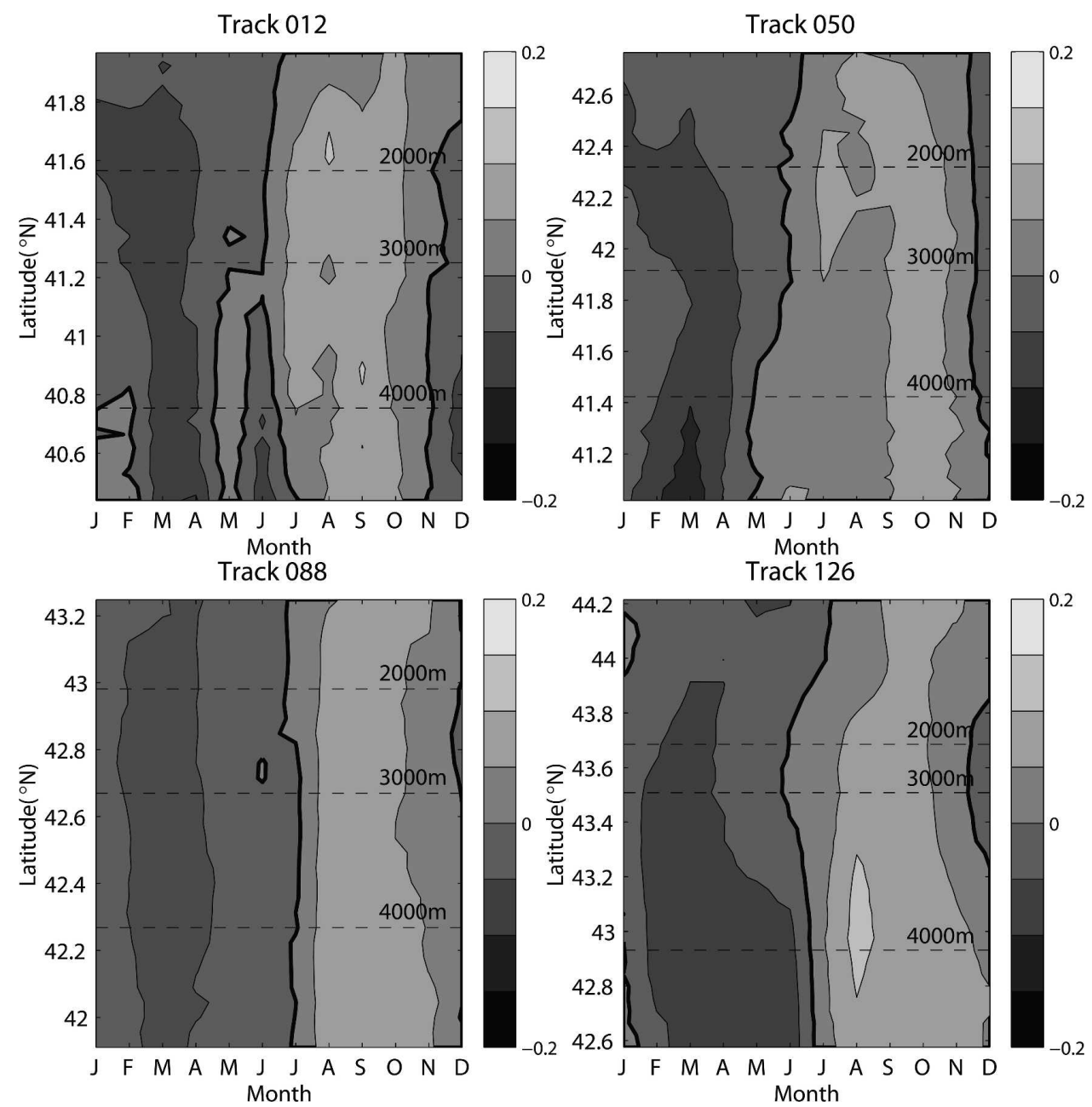

FIG. 5. Along-track distributions of monthly sea level anomalies (m) from T/P data. The zero contour is depicted as the thick line.

a mean circulation field from numerical ocean models. In this study we have used climatological mean currents based on Han et al.'s (1997) diagnostic finite-element model solutions as the mean circulation field. The model consists of the nonlinear three-dimensional shallow-water equations with hydrostatic and Boussinesq assumptions and a vertical eddy viscosity closure. Its forcing includes baroclinic pressure gradients from climatological seasonal mean density fields, $M_{2}$ tides, and spatially uniform seasonal mean wind stresses. The nonlinear three-dimensional equations were iteratively solved by a two-frequency harmonic method. The climatological mean currents are simple arithmetic averages of Han et al.'s (1997) winter, spring, and summer solutions and the fall (autumn) solution computed afterward, but using the same approach. We interpolated the climatological mean model surface currents onto the satellite ground tracks (Fig. 3). The components normal to the track are then derived to be added onto the T/P altimetric current anomalies. We can see a southwestward flow along the shelf edge and the upper continental slope and a northeastward current along the lower continental slope. The model results at the shelf edge are in good agreement with moored measurements (Fig. 3; Han et al. 1997). Nevertheless, it is likely that these model currents underestimate the mean flows offshore of the upper slope since the model used false bottom topography offshore of the 1000-m isobath and steric height relative to the false bottom as open boundary conditions (Han et al. 1997).

\section{c. Calculation of the total geostrophic transport}

Following Han and Tang (2001), we define the barotropic transport as the component associated with the bottom flow and the baroclinic transport as the depthvariable current referenced to the bottom flow. As 

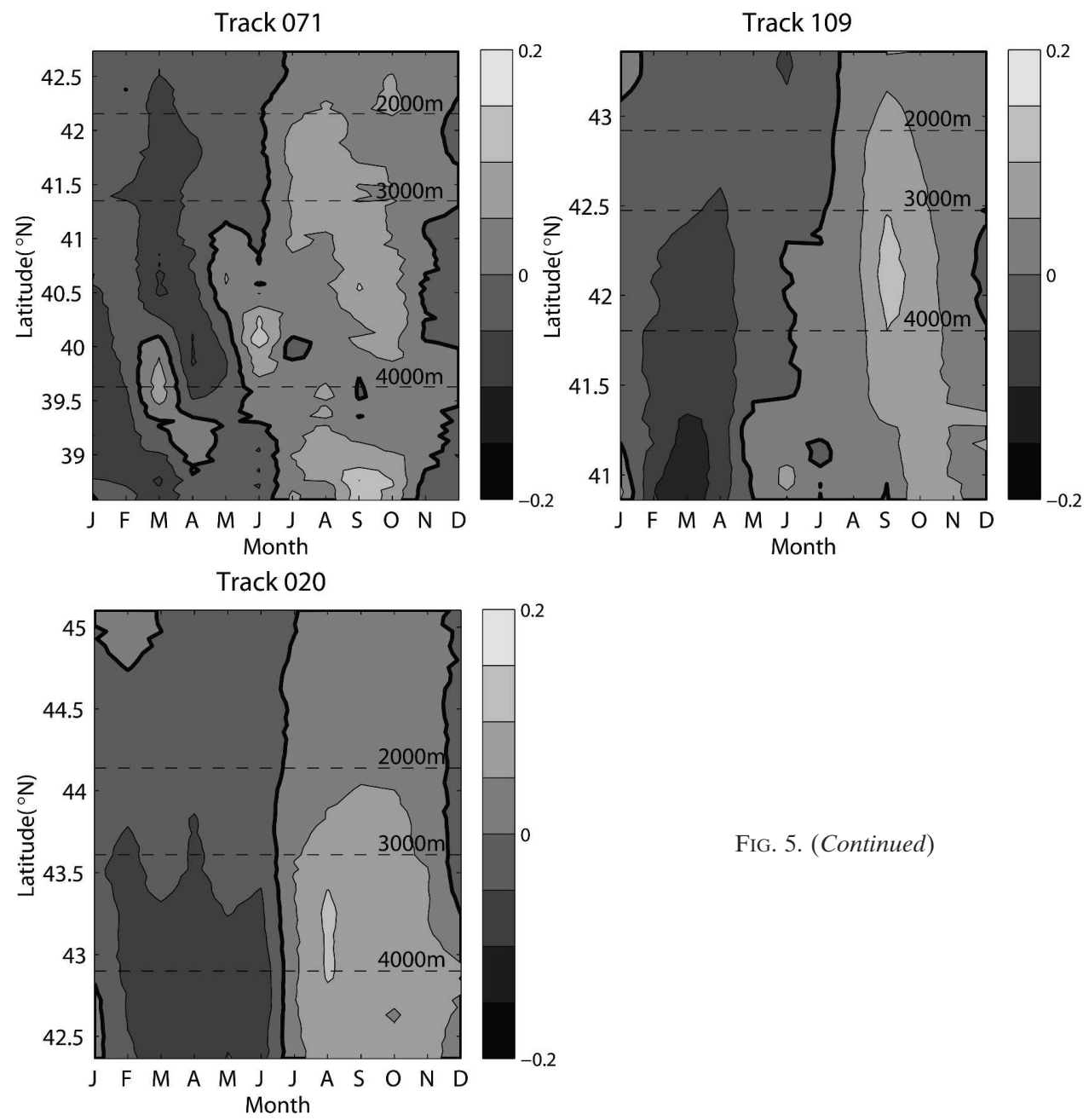

FIG. 5. (Continued)

such, the total transport (TT) = the barotropic component + baroclinic component. Here BT and BC are given by

$$
\begin{aligned}
\mathrm{BT} & =\frac{g}{f} \int_{x_{1}}^{x_{2}} \frac{\partial \zeta}{\partial x} H d x+\frac{1}{f} \int_{x_{1}}^{x_{2}} H \int_{-H}^{0} \frac{\partial b}{\partial x} d z d x, \\
\mathrm{BC} & =\frac{1}{f} \int_{x_{1}}^{x_{2}} \int_{-H}^{0} z \frac{\partial b}{\partial x} d z d x, \text { and } \\
b & =\frac{g}{\rho 0}[\rho(x, z)-\bar{\rho}(z)],
\end{aligned}
$$

where $x$ is the horizontal coordinate along the transect with $x=0$ at the 200-m isobath increasing offshore $\left(x_{1}\right.$ and $x_{2}$ are lower and upper limits of the integration along the transect), $f$ is the Coriolis parameter, $z$ is the vertical coordinate positive upward with $z=0$ at the mean sea level, $g$ is the gravity acceleration, $\rho$ is the density of water, $\rho_{0}$ is the reference density, $b$ is the buoyancy parameter, $\bar{\rho}(z)$ is a reference density obtained by averaging $\rho$ at a given depth across the transect, $H$ is the local water depth, and $\zeta$ is the sea surface height referenced to an ocean geoid, adjusted for the effect of the local atmospheric pressure. The two terms in BT are associated with the sea surface slope measured by T/P (the first term) and with the density variation (the second term).

The density data are from Tang and Wang's (1996) seasonal mean climatology for the northwest Atlantic. The climatology was generated on a grid resolution of $1 / 6^{\circ} \times 1 / 6^{\circ}$ from the Atlantic Fisheries Adjustment Program temperature and salinity database archived at the Bedford Institute of Oceanography, by using an objective analysis method with an iterative difference correction procedure that has topography-dependent radii of influence. 


\section{d. Estimation of frontal positions and WCR's kinematics}

We have also used frontal analysis data that quantitatively define the location of surface temperature fronts (shelf-slope front, Gulf Stream rings, and Gulf Stream northern boundary) based on satellite imagery (e.g., Drinkwater et al. 1994). The shelf-slope front is the narrow boundary separating cool shelf water from the warmer slope water immediately offshore; the Gulf Stream rings are anticyclonic, warm-core eddies pinched from the Gulf Stream; and the Gulf Stream northern boundary separates the stream from the slope water. Frontal positions were digitized from NOAA "Oceanographic Features Analysis" charts in and before September 1995 (K. Drinkwater and R. Pettipas 2001, personal communication). Since April 1996, the charts have been referred to as "Jennifer Clark's Gulf Stream." No data are available in between.

After digitization, the frontal positions were checked for consistency and edited where necessary. Time series of latitudinal displacement of the Gulf Stream northern boundary and the shelf-slope front were generated at each degree of longitude. Occasionally the shelf-slope front and the Gulf Stream can cross a given degree of longitude more than once. For the former, the position was taken as the northernmost boundary minus the distance of shelf water seaward of this boundary for the former and as the average latitude of the crossings for the latter. See Drinkwater et al. (1994) for more detail.

Figure 4 shows the shelf-slope front, the Gulf Stream northern boundary, and warm temperature patches with some of them associated with Gulf Stream WCRs, for the week of 1 June 1993. We can see that the instantaneous shelf-slope front and Gulf Stream northern boundary (Fig. 4) are significantly deviated from their mean positions (Fig. 3). Three Gulf Stream rings are apparent over the continental slope and rise, with a distinct anticyclonic circulation.

We have examined the T/P and frontal analysis data year by year from 1993 to 2001 for the interannual variability of some WCR's properties. WCRs in the present study are identified by combining the frontal analysis data and altimetric data. On average, frontal position data are available every 2-3 days, while T/P data are available every 10 days. From the frontal analysis data, we estimated the center and radius of a potential WCR. The center of a ring is calculated by averaging geographical coordinates (longitude and latitude) of the points defining the edge of ring in the frontal analysis data. The ring radius is estimated by averaging distances between the points and the center. Given a T/P pass, we search from the frontal analysis data for WCRs
TABLE 1. Means and rms values $(\mathrm{cm})$ of seasonal-mean T/P sea level anomalies (positive upward), seasonal-mean steric height anomalies, and their differences over the Scotian slope.

\begin{tabular}{lrrrr}
\hline \hline & Winter & Spring & Summer & Fall \\
\cline { 2 - 5 } & \multicolumn{5}{c}{ Mean } \\
\hline T/P & -5.17 & -3.08 & 5.76 & 3.02 \\
Steric & -5.26 & -4.49 & 4.52 & 5.22 \\
Difference & 0.09 & 1.41 & 1.24 & -2.21 \\
& & Rms & & \\
T/P & 5.43 & 3.67 & 6.15 & 3.56 \\
Steric & 5.97 & 4.77 & 5.04 & 5.35 \\
Difference & 2.63 & 2.7 & 3.24 & 2.65 \\
\hline
\end{tabular}

with an average radius of greater than $75 \mathrm{~km}$ and with their centers within $30 \mathrm{~km}$ of the pass, with a time window of \pm 2 days relative to the $\mathrm{T} / \mathrm{P}$ passing day. The results were further checked manually to ensure consistency.

The relative vorticity associated with its interior core is derived (normalized with the planetary vorticity $f$ ) and the rms current magnitude within the ring perimeter is calculated from the T/P cross-track current anomalies on the passing track (Han 2004b).

\section{Seasonal variability}

\section{a. Sea level}

The T/P sea level anomalies at each location are averaged monthly over all years and are plotted in the month-latitude domain for each track (Fig. 5). There are large seasonal changes with sea level higher in summer and lower in winter. The magnitudes generally increase westward and offshore. Typical ranges are $10 \mathrm{~cm}$ for the upper slope and up to $20 \mathrm{~cm}$ for the lower slope. The seasonal cycle seems to be associated with the thermal expansion and contraction as a result of solar heating and advection (Han et al. 2002). The present monthly means are not only consistent with the annual sea level harmonic of Han et al. (2002) from an earlier version of $\mathrm{T} / \mathrm{P}$ sea level data but also provide more information on intraseasonal variability. There is enhanced intraseasonal change over the lower continental slope, which may be associated with the fluctuation of the Gulf Stream north-south position or with the aliasing of mesoscale WCRs.

Steric height profiles on the T/P ground tracks over the Scotian slope are calculated relative to the sea bottom (with the normal velocity equal to zero at the bottom) from seasonal-mean density climatology (Tang and Wang 1996). Seasonal-mean steric height anomalies are computed by subtracting the steric heights from 
(a)
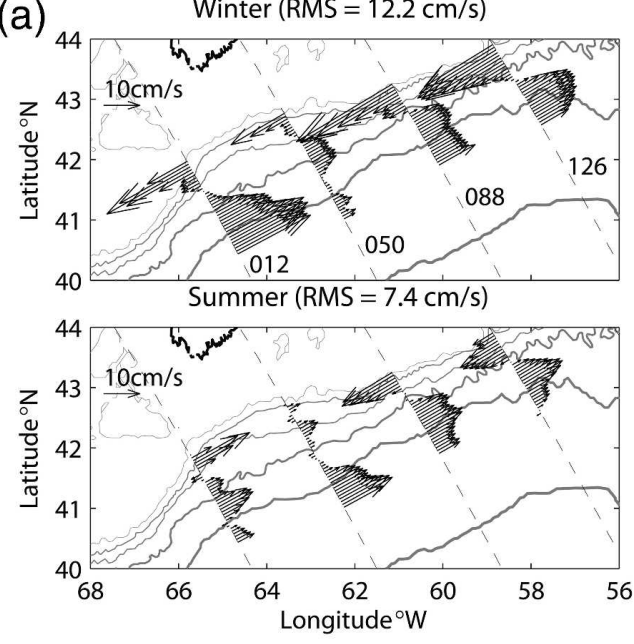

(b)
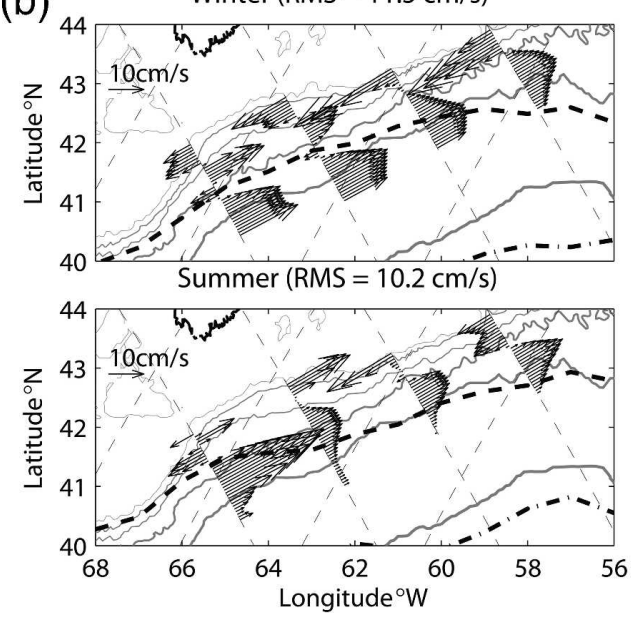

(c)
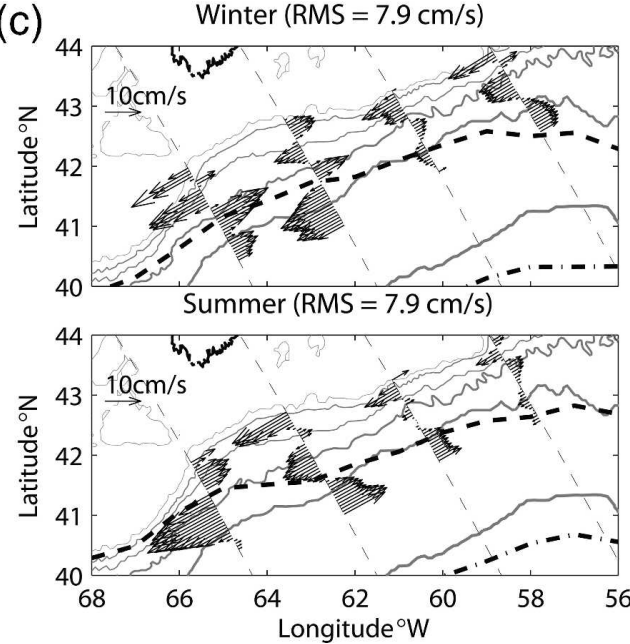

Spring (RMS $=7.8 \mathrm{~cm} / \mathrm{s}$ )

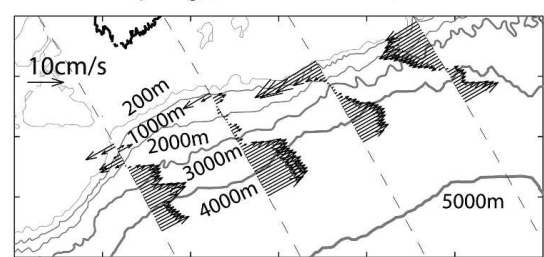

Fall (RMS $=10.6 \mathrm{~cm} / \mathrm{s})$

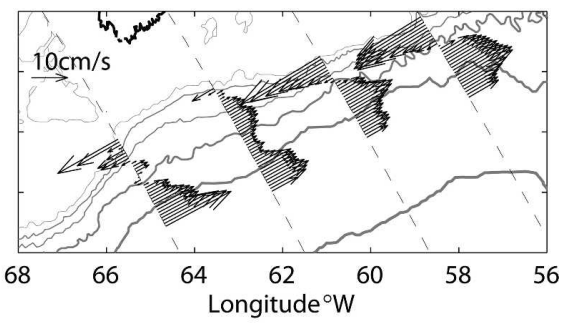

Spring (RMS $=8.7 \mathrm{~cm} / \mathrm{s})$

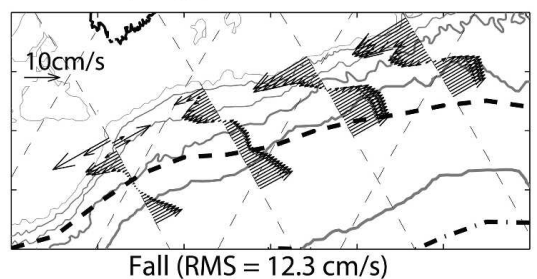

Fall (RMS $=12.3 \mathrm{~cm} / \mathrm{s})$

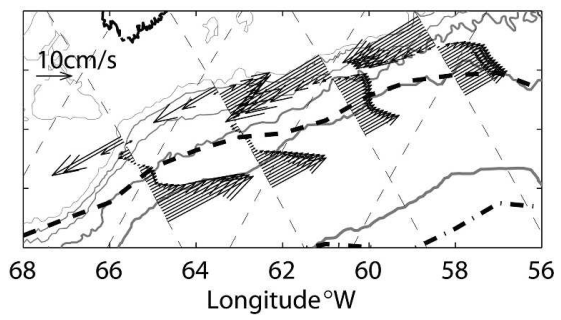

Spring (RMS $=5.2 \mathrm{~cm} / \mathrm{s}$ )

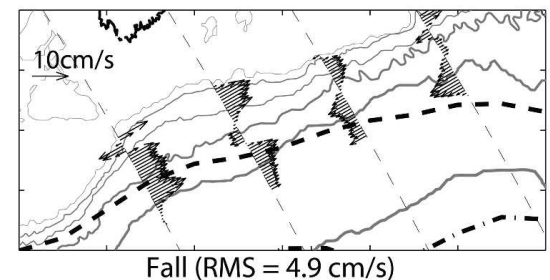

Fall $(\mathrm{RMS}=4.9 \mathrm{~cm} / \mathrm{s})$

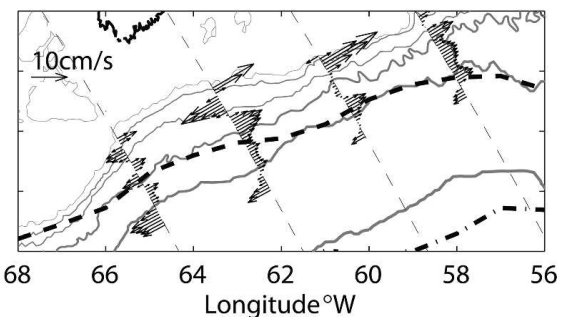

FIG. 6. (a) Seasonal mean currents over the Scotian slope in winter, spring, summer, and fall: altimetric seasonal mean anomalies plus Han et al.'s (1997) climatological model means. (b) Climatological seasonal mean current anomalies in winter, spring, summer, and fall over the Scotian slope from Han et al.'s (1997) model solutions. (c) The altimetry minus model differences are for the four seasons. Also depicted in (b) and (c) are positions of the shelf-slope front (thick dashed lines) and the Gulf Stream northern boundary (dash-dotted line) for each season. 
(a) $200-2000 m$

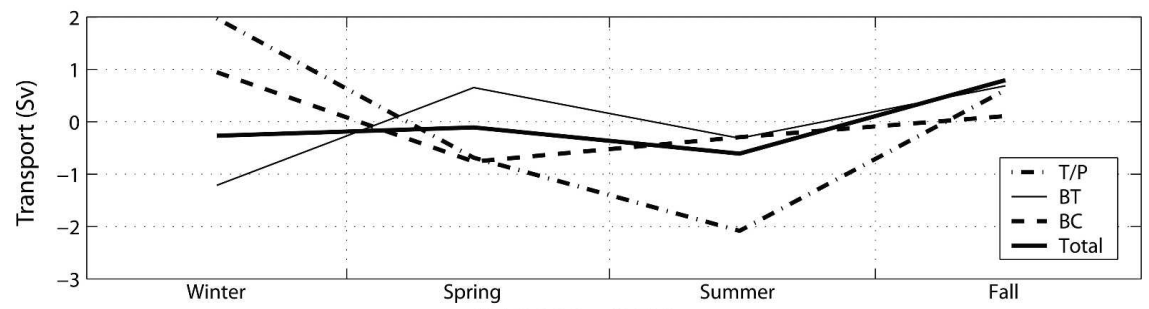

(b) $2000-4500 m$

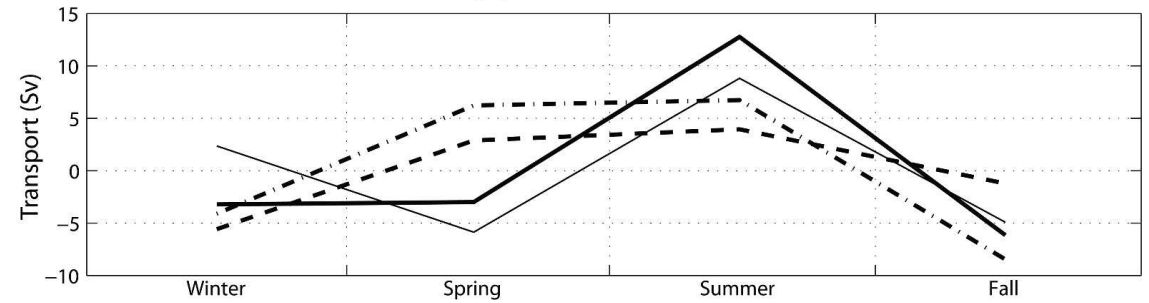

FIG. 7. Seasonal mean transport anomalies (positive westward) associated with the shelfedge (200-2000 m) current and the slope (2000-4500 m) current from the T/P sea level data and Tang and Wang's (1996) density climatology. The results are the averages for Tracks 012, 050, 088, and 126 .

their annual mean field. The steric height (not shown) is higher in summer/fall and lower in winter/spring, consistent with altimetric data. The along-slope and crossslope distribution of the steric height anomalies closely resembles that of the altimetric results. We have also calculated the difference between steric height anomalies and T/P sea level anomalies after interpolating the former onto T/P data points. Statistics averaged for the four tracks are given in Table 1. Overall, the mean and rms values for the steric heights are close to those of the altimetric height anomalies, which indicates that the steric height can approximately account for seasonal altimetric sea level variability over the Scotian slope. The differences may be, in part, due to the arbitrariness of the bottom reference in calculating the steric height in addition to errors in altimetric and hydrographic data and to barotropic effects in altimetric data. A barotropic North Atlantic wind-driven circulation model indicated that the seasonal sea level range could reach $3 \mathrm{~cm}$ (Han 2005) over the Scotian slope. Therefore, the barotropic component can account for a significant portion of the estimated differences between $\mathrm{T} / \mathrm{P}$ and steric height.

\section{b. Currents}

Altimetric seasonal-mean current anomalies (January-March, April-June, July-September, and OctoberDecember for winter, spring, summer, and fall, respectively) averaged over all years were calculated from the $\mathrm{T} / \mathrm{P}$ current anomaly data. Long-term seasonal-mean current fields (Fig. 6a) were then constructed by adding the climatological-mean model flows (Han et al. 1997) to the T/P seasonal mean anomalies. The southwestward shelf edge current is strongest in winter/fall and weakest in spring/summer. The seasonal range amounts to $10-20 \mathrm{~cm} \mathrm{~s}^{-1}$. The eastward slope current [with the mean current toward the northeast (Fig. 4)] over the lower continental slope in the vicinity of the 4000-m isobath seems stronger in winter/fall, except for Track 050 in winter. The rms current magnitude of the longterm seasonal means is $12.2,7.8,7.4$, and $10.6 \mathrm{~cm} \mathrm{~s}^{-1}$ for winter, spring, summer, and fall, respectively.

Figure 6b presents Han et al.'s (1997) seasonal mean currents over the Scotian slope. The model rms current magnitude is $11.5,8.7,10.2$, and $12.3 \mathrm{~cm} \mathrm{~s}^{-1}$ for winter, spring, summer, and fall, respectively. In general, the model results show stronger southwestward shelf-edge flow and northeastward slope water current in winter/ fall, similar to the altimetry results in Fig. 6a. However, there are notable discrepancies in some areas (Fig. 6c). The model - T/P rms current difference is 7.9, 5.2, 7.9, and $4.9 \mathrm{~cm} \mathrm{~s}^{-1}$ for winter, spring, summer, and fall, respectively. The discrepancies can be due to either inadequacies of the model or errors in the data. In addition, the altimetry results provide geostrophic current estimates for the period from 1992 to 2000, while the model solutions represent a climatological seasonalmean realization diagnosed from temporarily and spatially scarce density data.

Using the sea surface as the level of known motion (under geostrophy) derived from the T/P altimetry 

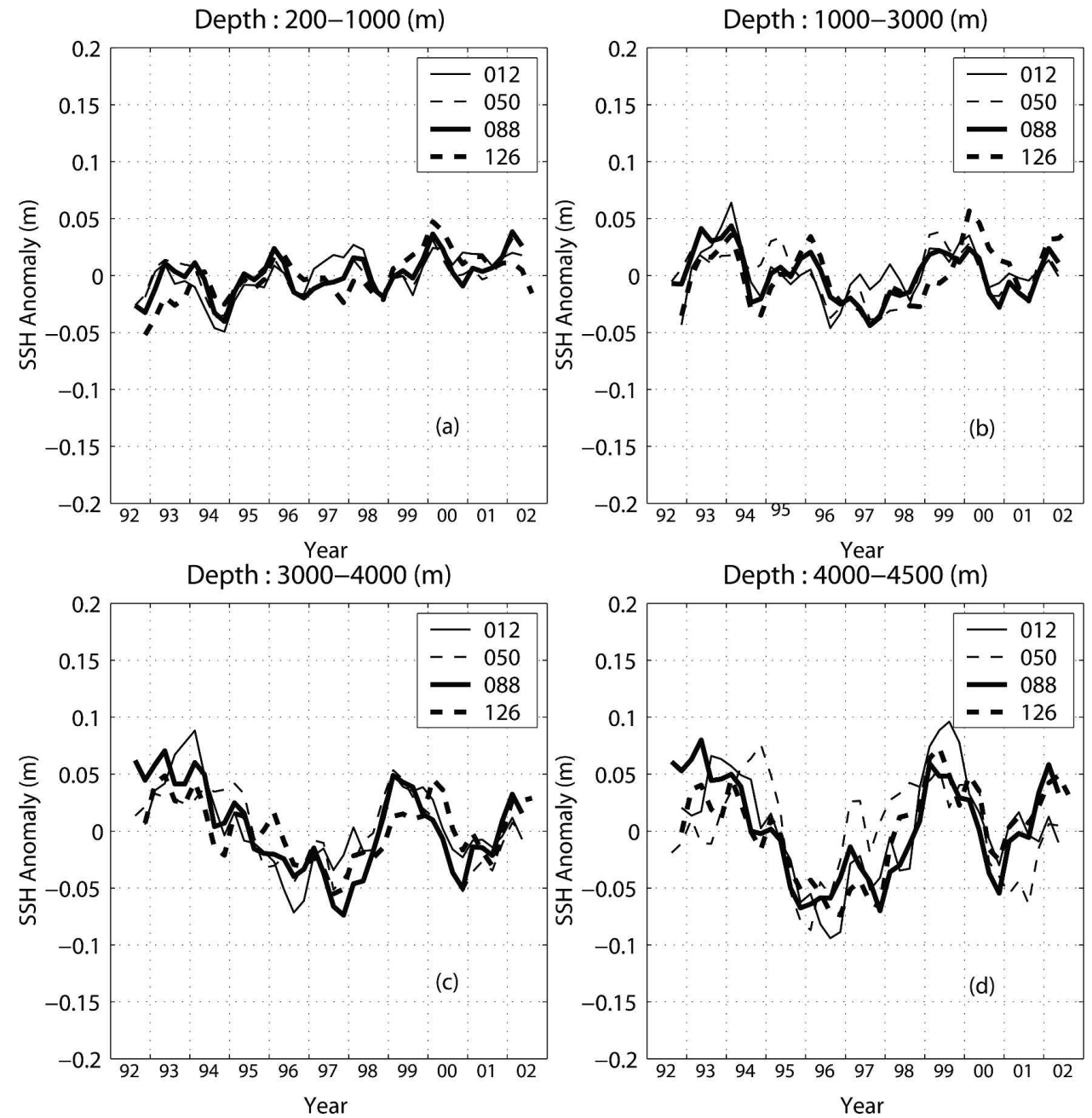

FIG. 8. Seasonal T/P sea level anomalies over the Scotian slope by season and year, averaged for four segments based on bathymetry. The seasonal means are smoothed with a five-point moving filter.

(Han and Tang 1999, 2001), we have estimated seasonal transport changes of the shelf-edge current (from the 200- to 2000-m isobath) and that of the slope current (from the 2000- to 4500-m isobath) for the four tracks using the method illustrated in section $2 c$. The values from the four tracks have been averaged to represent an overall pattern for the Scotian slope, as shown in Fig. 7.

For the westward shelf-edge current (Fig. 7a), the seasonal cycle of the total transport follows that of the barotropic component. The shelf-edge transport was largest in fall and smallest in summer. The fall - summer difference is about $1.5 \mathrm{~Sv}\left(\mathrm{~Sv} \equiv 10^{6} \mathrm{~m}^{3} \mathrm{~s}^{-1}\right)$. The present study reveals substantial compensation of the barotropic with baroclinic components, and did not show the stronger winter transport as indicated by Han et al.'s (1997) modeling study. Note that among the four individual tracks the seasonal cycle has significant dif- ferences in magnitude and phase. The differences may be due in part to the arbitrariness of choosing the isobath as the criterion for the spatial bound and to the aliasing of eddy variability, but an examination of the differences is beyond the scope of the present paper. On the other hand, the baroclinic component is stronger in winter/fall and weaker in spring/summer with a range of about $2 \mathrm{~Sv}$, more consistent with Han et al.'s (1997) model estimates.

For the eastward slope current from the 2000- to 4500-m isobath (Fig. 7b) the total transport, dominated by the barotropic component, seems to be large in winter/spring/fall and small in summer. The seasonal range is $15-20 \mathrm{~Sv}$. The baroclinic component with a range of some $8 \mathrm{~Sv}$ is larger in winter/fall and smaller in spring/ summer. The present study reveals an overall barotropic and baroclinic reinforcement of the seasonal cycle 
and, for the first time, provides an observationally based estimate of the seasonal cycle of the slope-water current transport.

\section{Interannual variability}

\section{a. Sea level}

For each cross-slope ground track the T/P sea level anomalies at each location are first averaged seasonally and then averaged spatially for the four slope segments based on bathymetry: (i) 200-1000 m (Fig. 8a), (ii) 1000-3000 m (Fig. 8b), (iii) 3000-4000 m (Fig. 8c), and (iv) $4000-4500 \mathrm{~m}$ (Fig. $8 \mathrm{~d}$ ). The seasonal, spatially averaged anomalies are further smoothed using a temporal five-point moving filter.

Over the lower continental slope and rise, the sea level variation had a pronounced interannual cycle with an increasing magnitude toward deeper waters (Figs. 8 b-d). Sea level variations on all four tracks showed a significant sea level fall from 1994 to 1996, with a rapid rebound after 1997. The sea level range amounts to 10-20 cm. However, notable differences among the tracks exist in sea level fluctuations at shorter time scales. Over the shelf edge and upper continental slope between the 200-m and 1000-m isobaths (Fig. 8a), the sea level showed an overall rising trend, with less variability at short time scales than that over the lower slope and rise. Han (2002) reported that the sea level change over the Scotian slope offshore of the 1000-m isobath was almost out of phase with that over the Scotian shelf.

The satellite infrared data indicate significant interannual variations of the frontal positions in the study period (Fig. 9a). The Gulf Stream northern boundary and the shelf-slope front were in their most northern position in the early 1990s until the end of 1995 when the winter North Atlantic Oscillation (NAO) index (Osborn 2004) was higher (Fig. 9b). There was an abrupt southward movement of the Gulf Stream from 1995 to 1996 associated with the dramatic weakening of the NAO. On average, the north-south range was about $50 \mathrm{~km}$. The dynamic mechanisms of the origin and consequence of the movement is beyond the scope of the present paper. Nevertheless, the sea level changes may schematically and to the lowest order be explained as the consequence of the north-south shift of the frontal positions. A typical mean steric height profile across the Scotian slope is illustrated in Fig. 10, based on Tang and Wang's (1996) temperature and salinity climatology. The sea level increases toward the coast and the deep ocean with the lowest value near the 3000-m isobath. Considering the north-south shift of the Gulf Stream and shelf-slope front (and neglecting
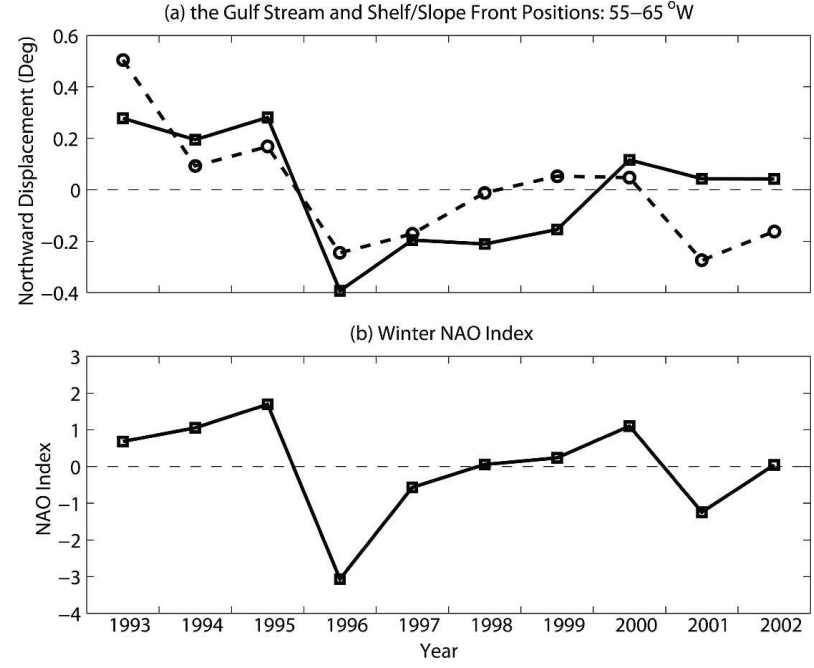

FIG. 9. (a) Annual anomalies of the Gulf Stream northern boundary (square) and the shelf-slope front (circle) positions: $55-65^{\circ} \mathrm{W}$, (b) the winter (December, January, February, and March) NAO index, calculated as the normalized winter sea level pressure difference between the Azores high and the Icelandic low.

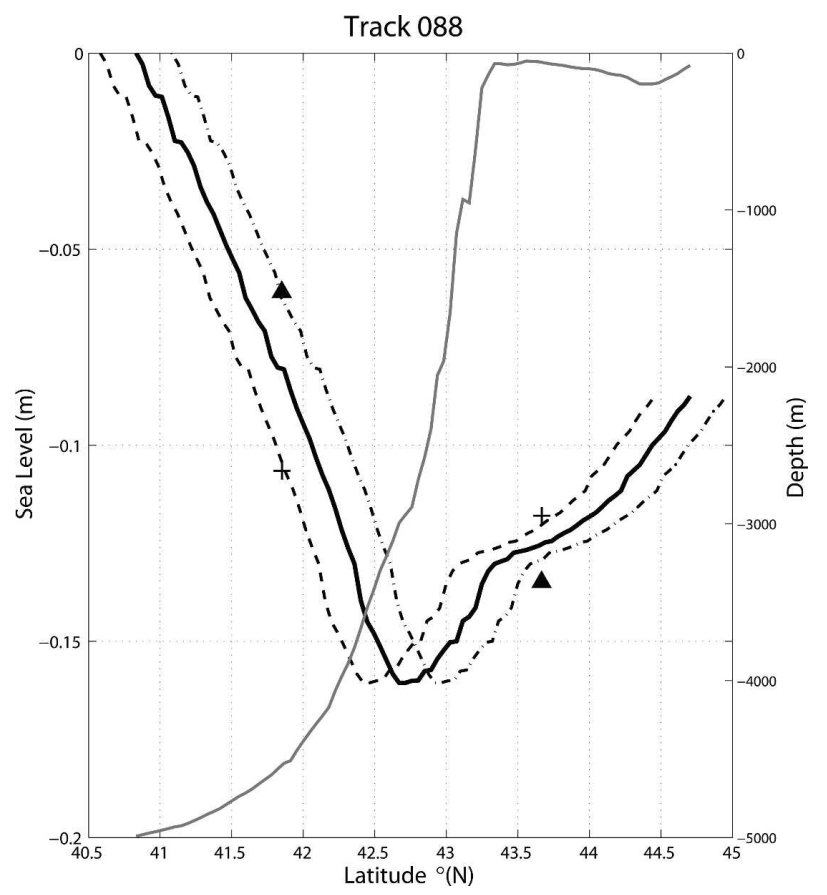

FIG. 10. Sea level profiles along Track 088 across the Scotian shelf and slope. The thick solid line is the steric height based on Tang and Wang's (1996) annual mean density climatology. The dash-dotted and dashed lines represent the northern and southern Gulf Stream position scenarios, respectively. The triangles are the spatial averages north and south of the lowest point for the former scenario and the crosses are those for the latter. The gray line is the bottom topography. 

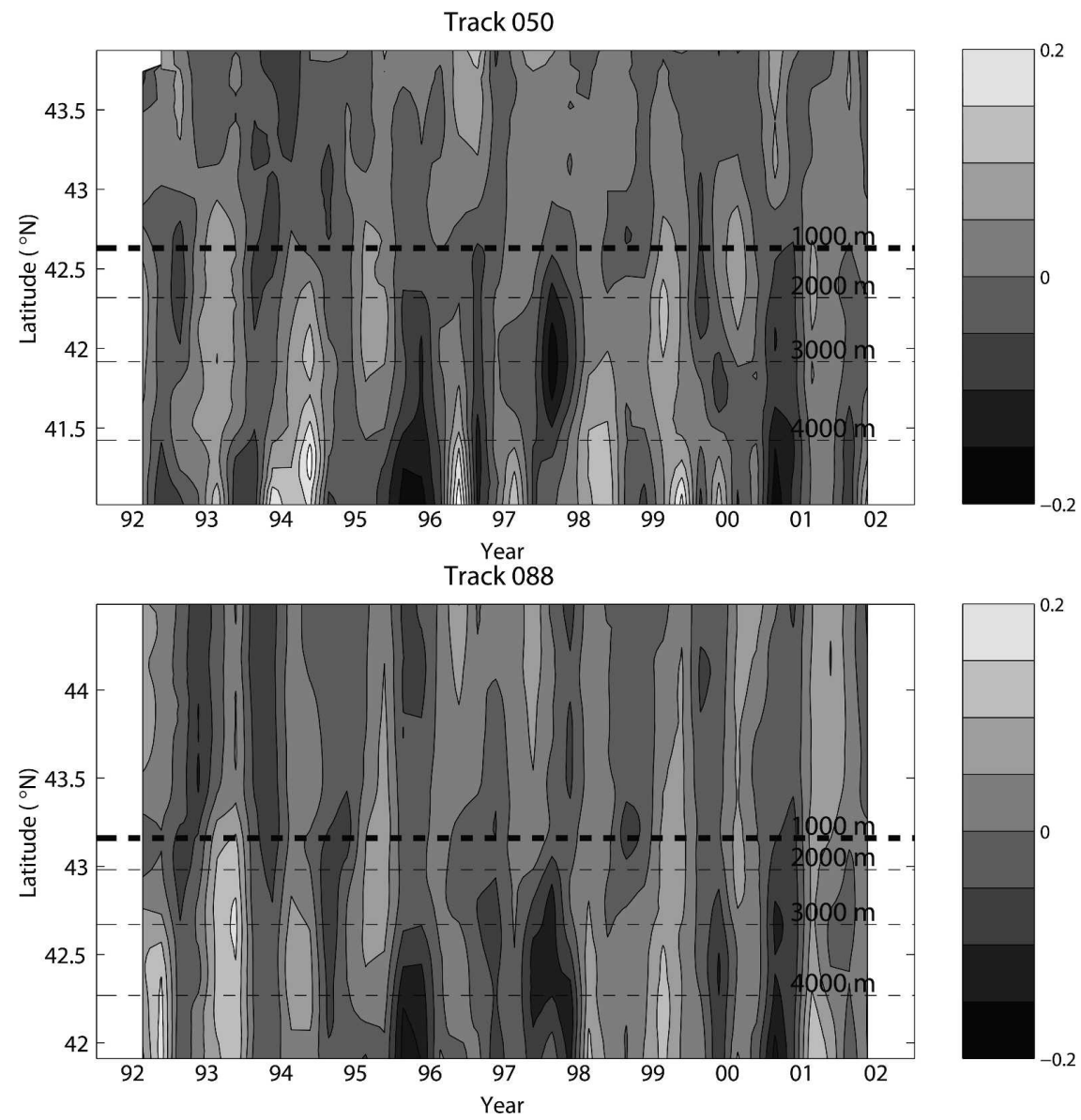

FIG. 11. Seasonal T/P sea level anomaly $(\mathrm{m})$ distribution over the Scotian slope in the time-latitude domain for Tracks 050 and 088, including both the Scotian shelf and slope. The seasonal mean anomalies are smoothed with a five-point moving filter. The dashed lines indicate water depths.

any local dynamical adjustment and interaction with the Labrador Current), the location of the lowest sea level would be more onshore in the early 1990s and more offshore in 1996 (Fig. 10). It is clearly evident that the sea level over the lower continental slope in 1996 would be lower than that in the early 1990s.

A further examination of the time-latitude plot of sea level for the central and western Scotian shelf tracks (Fig. 11) reveals more detail of the cross-shelf structure of sea level variation. Sea level is highly coherent across the slope with an increased magnitude offshore. The temporal and spatial patterns indicate the importance of mesoscale variability associated with meanders and WCRs of the Gulf Stream over the Scotian slope. The difference between the shelf and slope is significant in certain periods. In particular, there were large sea surface slope anomalies (upward toward the coast) over the shelf edge and the upper continental slope in 1997 and early 1998, which are associated with intensified shelf-edge currents (Fig. 12; see section 4b for detail) during this period since the mean shelf-edge flow normal to the track is directed southwestward (Fig. 3).

\section{b. Currents}

From section $3 b$ the seasonal surface slope circulation seems to be strongest in the winter. Therefore, we choose to examine winter altimetric currents for the interannual changes from 1993 to 2002.

The results (Fig. 12) clearly show that the winter mean currents were strongest in 1998 with the maximum currents up to $30 \mathrm{~cm} \mathrm{~s}^{-1}$ for both the shelf-edge current and the slope current. The rms magnitude in winter 1998 is $20.7 \mathrm{~cm} \mathrm{~s}^{-1}$, which is nearly 2 times as large as the long-term winter-mean current magnitude of $12.2 \mathrm{~cm} \mathrm{~s}^{-1}$ (Fig. 6). The current in 1996 was weakest (with an rms magnitude of $10.4 \mathrm{~cm} \mathrm{~s}^{-1}$ ), with broader southwestward flows across the slope from the 200-m to 4000-m isobath. The eastward slope current (not 

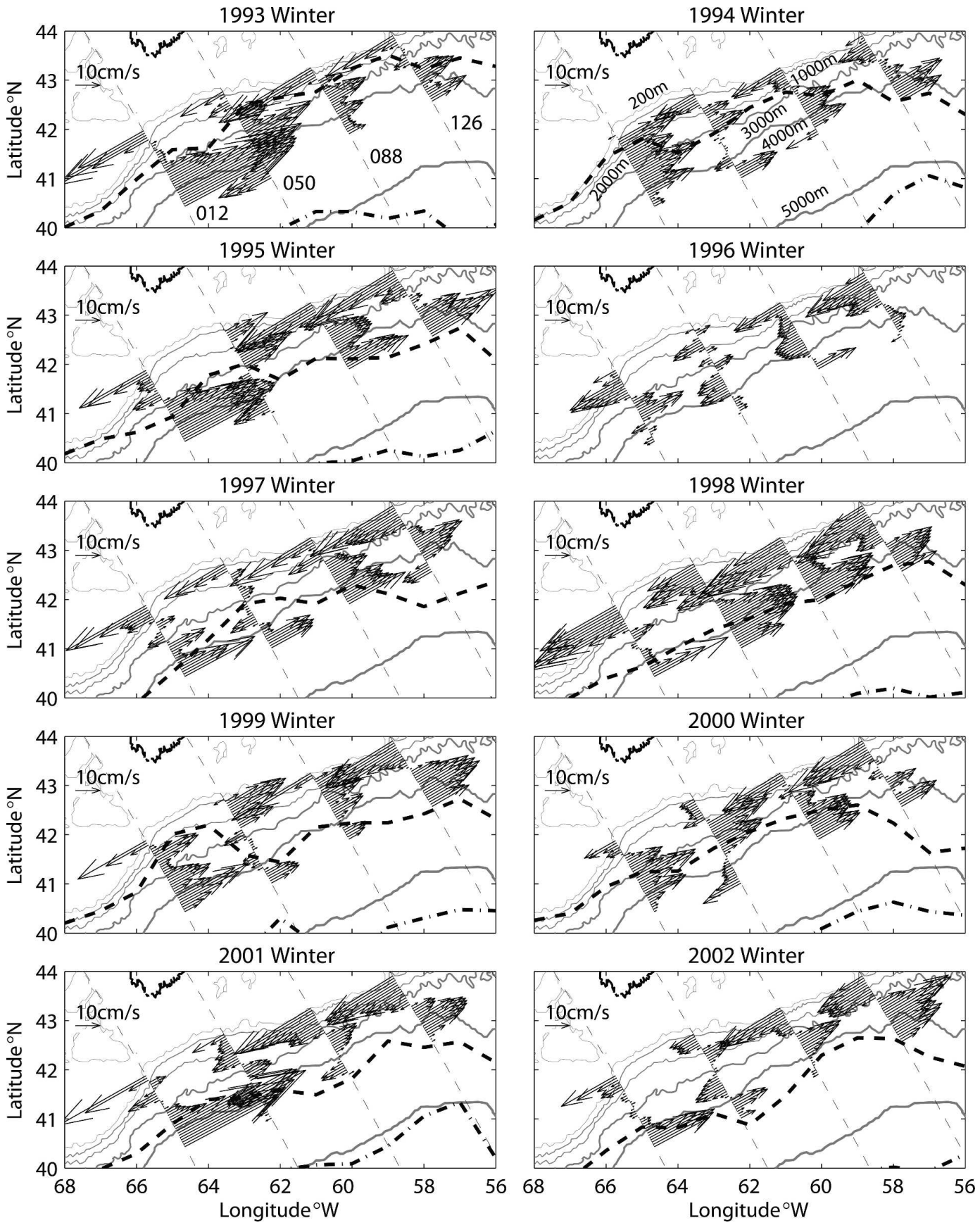

FIG. 12. Winter current fields from altimetric seasonal-mean anomalies and Han et al.'s (1997) climatological model means over the Scotian slope. Also depicted are positions of the shelf-slope front (thick dashed lines) and the Gulf Stream northern boundary (dash-dotted lines) in individual winters.

shown) is located farther offshore. The shelf-slope front was very close to the shelf edge in 1993. It separates the westward shelf-edge current with the eastward slope current. The shelf-slope front started to move southward in 1994. From 1995 on, the shelf-slope front was located near the 4000-m isobath and much of the slope current was inshore of it. It is assumed that the closer proximity of the shelf-slope front to the shelf edge in the early 1990s suppressed the penetration of the Labrador Current from the Newfoundland toward the Scotian slope and allowed the full development of the eastward slope current. The shift of the shelf-slope front was not sufficient to change the flow regime. The southern shift of the Gulf Stream in 1996 broke the 

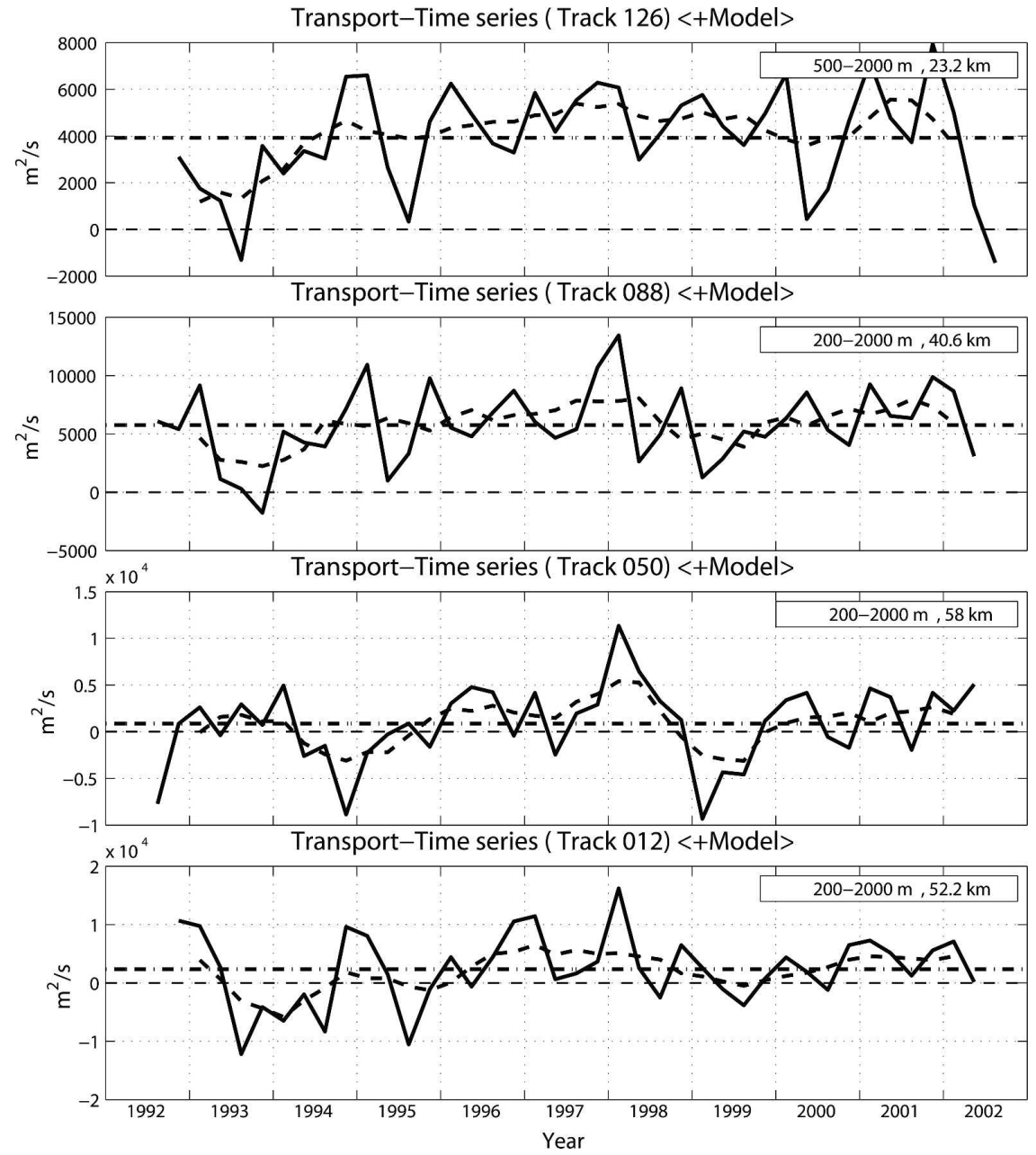

FIG. 13. Surface (unit depth) volume transport (solid line, positive southwestward) between the 200-m (500 $\mathrm{m}$ for Track 126) and 2000-m isobaths from altimetric seasonal-mean anomalies and Han et al.'s (1997) climatological model means (thick dash-dotted line). The dashed line shows interannual variability after the annual and semiannual cycles are removed and a five-point moving filter is applied to the altimetric seasonal-mean anomalies.

balance and resulted in a weaker but broader southwestward flow across the Scotian slope. The gradual northward retreat of the Gulf Stream in 1997/98 restored the earlier dynamic balance and the anticyclonic tendency over the Scotian slope, while the arrival of the Labrador Current pulse intensified the overall slope water circulation (Han 2002), leading to the strongest westward shelf-edge current and eastward slope current in the 1990s.

To further illustrate the interannual variability associated with shelf-edge current, monthly mean surface volume transport is calculated for segments based on bathymetry. The calculated transport values can nominally represent the strength of the shelf-edge current, although the current is depth variable. After annual and semiannual cycles are removed, the monthly means are averaged to obtain seasonal means by season and year, which are then smoothed by a five-point moving filter. There is significant interannual transport change (Fig. 13) associated with the shelf-edge current. The transport was largest in 1997/98, which supports Han's (2002) hypothesis of a Labrador Current pulse traveling through the Scotian slope and intruding onto the Scotian shelf in 1997/98. The intensification is consistent with an intensified equatorward shelf-edge current on the Newfoundland slope in 1996/97 (Han 2006) and a colder and stronger westward current off St. Pierre Bank in 1997 (P. C. Smith 2000, personal communication).

The yearly rms surface current magnitude over the Scotian slope also had prominent interannual changes (Fig. 14). The current magnitude was smallest in 1996- 


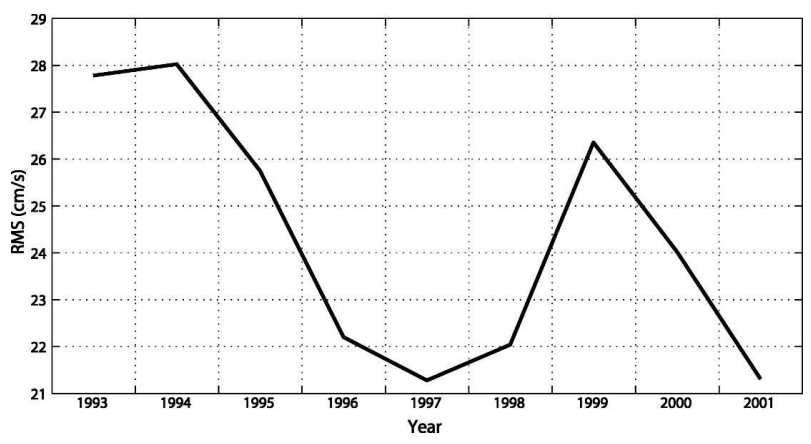

FIG. 14. Rms surface current magnitude over the Scotian slope (from the 200- to 4500-m isobaths). The surface current is the sum of the T/P altimetric anomalies and Han et al.'s (1997) climatological mean.

98 and 2001 at $22 \mathrm{~cm} \mathrm{~s}^{-1}$ and largest at about $28 \mathrm{~cm} \mathrm{~s}^{-1}$ in 1993 and 1994. The yearly variation of the rms surface current magnitude was different from that of either the seasonal-mean shelf-edge current or the seasonalmean slope current. The difference is not surprising because the former includes intraseasonal and mesoscale eddy variability but the latter does not. Instead, it implies different underlying mechanisms for the different temporal and spatial scales. While the interannual variability of the seasonal mean currents appears to be related to the Labrador Current and the Gulf Stream north-south position, that of the rms current over the Scotian slope was probably related to the Gulf Stream WCRs, which were also found to contribute to the westward increase of the Scotian slope surface current magnitude (Han 2004a). We have calculated the yearly percentage occurrence of WCRs in a given year as the ratio of the number of days when a ring's average radius is 90 $\mathrm{km}$ or larger and its average center is located inside a predefine area (see Fig. 4) to the number of days on which observations were available. We also calculated the percentage occurrence with average radii of greater than 60 and $120 \mathrm{~km}$, respectively, and found that the relative occurrence among the years is insensitive to the choice of the radius. There is evidently positive correlation between the rms current variability and the WCRs occurrence over the Scotian slope on the interannual scale (Fig. 15). Note that any bias resulted from missing WCR data from September 1995 to April 1996 is minor given the relatively limited seasonality in the WCR occurrence. The general pattern is that the stronger the NAO (Fig. 9b), the more northerly the position of the Gulf Stream, the more WCRs over the Scotian slope, and the larger the rms current magnitude.

The yearly mean statistics for the radius, rms current magnitude, and normalized vorticity of the WCRs are summarized in Table 2. Although the percentage oc-
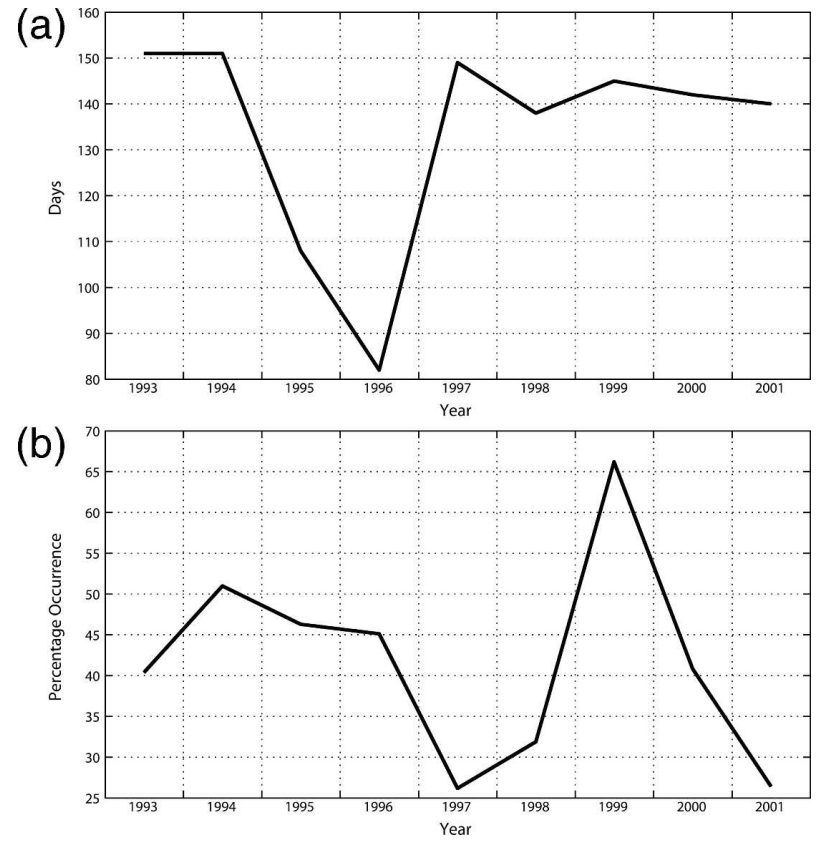

FIG. 15. The occurrence of WCRs over the Scotian slope: (a) total number of observed days by year, and (b) percentage occurrence.

currence is different year by year (Fig. 15), there appear to be little interannual differences for the mean diameters, rms current magnitude, and vorticity. The mean radius, rms current magnitude, and normalized vorticity are about $90 \mathrm{~km}, 52 \mathrm{~cm} \mathrm{~s}^{-1}$, and 0.16 . Therefore, it seems that the elevated occurrence of the WCRs increased the rms current magnitude during the early and late 1990s.

\section{Summary}

We have used T/P altimeter data for the period from 1992 to 2002 to study sea level and current variability over the Scotian slope. The T/P data have been combined with hydrographic data to calculate the seasonal changes of the total geostrophic transport and with sat-

TABLE 2. Yearly mean statistics of the Gulf Stream WCRs.

\begin{tabular}{cccc}
\hline \hline Year & $\begin{array}{c}\text { Radius } \\
(\mathrm{km})\end{array}$ & $\begin{array}{c}\text { Rms current } \\
\left(\mathrm{cm} \mathrm{s}^{-1}\right)\end{array}$ & $\begin{array}{c}\text { Normalized } \\
\text { vorticity }\end{array}$ \\
\hline 1993 & 90 & 50.2 & 0.16 \\
1994 & 92 & 51.1 & 0.17 \\
1995 & 86 & 53.1 & 0.17 \\
1996 & 93 & 56.3 & 0.16 \\
1997 & 93 & 54.0 & 0.16 \\
1998 & 93 & 54.4 & 0.17 \\
1999 & 96 & 53.6 & 0.16 \\
2000 & 87 & 51.6 & 0.17 \\
2001 & 92 & 51.0 & 0.16 \\
\hline
\end{tabular}


ellite frontal analysis data to estimate WCR properties. The results reveal significant seasonal and interannual variations in the sea level and surface geostrophic currents.

The sea level over the Scotian slope is higher in summer and lower in winter with larger magnitude offshore. Seasonal ranges are $10 \mathrm{~cm}$ for the upper slope and up to $20 \mathrm{~cm}$ for the lower slope. The shelf-edge surface current is larger in winter and smaller in summer, with a range of $10-20 \mathrm{~cm} \mathrm{~s}^{-1}$. Overall, the eastward surface slope current over the lower continental slope also seems to be stronger in winter/fall. The total transport associated with the westward shelf-edge current and with the eastward slope current, calculated by combining the T/P data with a climatological seasonalmean density field, reveals a substantial seasonal change dominated by the barotropic component.

A pronounced interannual variation of sea level over the Scotian slope and rise during the study period is evident, higher in the early 1990s, lowest in 1997/98, and rebounding afterward. The range increases offshore from nearly zero at the shelf edge to about $20 \mathrm{~cm}$ at the $4500-\mathrm{m}$ isobath. The year-to-year changes are also prominent in the altimetric geostrophic currents. The winter mean currents over the Scotian slope were strongest in 1997/98, with the westward shelf-edge current and the eastward slope current both reaching $30 \mathrm{~cm} \mathrm{~s}^{-1}$. Likewise, the nominal volume transport associated with the shelf-edge current exhibited a significant interannual cycle. The transport was largest in 1997/98. The Labrador Current strength, the Gulf Stream north-south position, and the occurrence of the WCRs are potential contributors to the interannual variability of the slope water circulation. The interannual variability of the rms current magnitude over the Scotian slope appears to be positively correlated with the occurrence of the Gulf Stream WCRs, while the yearly mean radius, rms current magnitude of the WCRs, and their vorticity do not show year-to-year differences.

Acknowledgments. I thank J. Li for assistance in data analyses, R. Pettipas for providing the frontal analysis data, and J. Helbig for useful comments. Helpful suggestions were received from the two anonymous reviewers. The project was funded through the Climate Change Impacts on the Energy Sector Program of the (Canadian) Federal Program for Energy, Research and Development (PERD), the Offshore Environmental Factor Program of PERD, and the GRIP Fund of the Canadian Space Agency. The T/P data were obtained from NASA Jet Propulsion Laboratory and Pathfinder Project.

\section{REFERENCES}

Benada, R., 1997: Merged GDR (TOPEX/Poseidon) user handbook. Jet Propulsion Laboratory Internal Document JPL D-11007, 124 pp.

Csanady, G. T., and P. Hamilton, 1988: Circulation of slopewater. Cont. Shelf Res., 8, 565-624.

Drinkwater, K. F., R. A. Myers, R. G. Pettipas, and T. L. Wright, 1994: Climatic data for the northwest Atlantic: The position of the shelf/slope front and the northern boundary of the Gulf Stream between $50^{\circ} \mathrm{W}$ and $75^{\circ} \mathrm{W}, 1973-1992$. Canadian Data Rep. of Fisheries and Ocean Sciences 12, iv + 103 pp.

Fratantoni, D. M., 2001: North Atlantic surface circulation during the observed with satellite-tracked drifters. J. Geophys. Res., 106, 22 067-22 094.

Han, G., 2002: Interannual sea level variations in the ScotiaMaine region in the 1990s. Can. J. Remote Sens., 28, 581-587. -, 2004a: Scotian slope circulation and eddy variability from TOPEX/Poseidon and frontal analysis data. J. Geophys. Res., 109, C03028, doi:10.1029/2003JC002046.

_ 2004b: TOPEX/Poseidon-Jason comparison and combination off Nova Scotia. Mar. Geod., 27, 577-595.

_ 2005: Wind-driven barotropic circulation off Newfoundland and Labrador. Cont. Shelf Res., 25, 2084-2106.

_ 2006: Low-frequency variability of sea level and currents off Newfoundland. Adv. Space Res., 38, 2141-2161.

— , and C. L. Tang, 1999: Velocity and transport of the Labrador Current determined from altimetric, hydrographic, and wind data. J. Geophys. Res., 104, 18 047-18 057.

— ern Labrador Sea based on TOPEX/Poseidon and WOCE data. J. Phys. Oceanogr., 31, 199-211.

_ _ M. Ikeda, and P. C. Smith, 1993: Annual variation of seasurface slopes over the Scotian shelf and Grand Banks from Geosat altimetry. Atmos.-Ocean, 31, 591-615.

_ C. G. Hannah, P. C. Smith, and J. W. Loder, 1997: Seasonal variation of the three-dimensional circulation over the Scotian shelf. J. Geophys. Res., 102 (C1), 1011-1025.

_ J. W. Loder, and P. C. Smith, 1999: Seasonal-mean hydrography and circulation in the Gulf of St. Lawrence and eastern Scotian and southern Newfoundland shelves. J. Phys. Oceanogr., 29, 1279-1301.

_ C. L. Tang, and P. C. Smith, 2002: Annual variations of sea surface elevations and currents over the Scotian shelf and slope. J. Phys. Oceanogr., 32, 1794-1810.

Joyce, T. M., 1991: Review of U.S. contributions to warm-core rings. Rev. Geophys., 29, 610-616.

Loder, J. W., J. A. Shore, C. G. Hannah, and B. D. Petrie, 2001: Decadal-scale hydrographic and circulation variability in the Scotia-Maine region. Deep-Sea Res. II, 48, 3-35.

Osborn, T. J., 2004: Simulating the winter North Atlantic Oscillation: The roles of internal variability and greenhouse gas forcing. Climate Dyn., 22, 605-623.

Petrie, B. D., and K. Drinkwater, 1993: Temperature and salinity variability on the Scotian shelf and in the Gulf of Maine 1945-1990. J. Geophys. Res., 98, 20 079-20 089.

Pickart, R. S., T. K. McKee, D. J. Torres, and S. A. Harrington, 1999: Mean structure and interannual variability of the slopewater system south of Newfoundland. J. Phys. Oceanogr., 29, 2541-2558.

Tang, C. L., and C. K. Wang, 1996: A gridded data set of temperature and salinity for the northwest Atlantic Ocean. Canadian Data Rep. of Hydrography and Ocean Science 148, 45 pp. 